\title{
Divergent coronary flow responses to uridine adenosine tetraphosphate in atherosclerotic ApoE knockout mice
}

\author{
Bunyen Teng ${ }^{1,2} \cdot$ Hicham Labazi $^{1,3}$ - Changyan Sun ${ }^{1,4}$ - Yan Yang ${ }^{5}$ Xiaorong Zeng ${ }^{5}$. \\ S. Jamal Mustafa ${ }^{1} \cdot$ Zhichao Zhou $^{1,6}(\mathbb{D}$
}

Received: 18 April 2017 / Accepted: 31 August 2017 /Published online: 20 September 2017

(C) The Author(s) 2017. This article is an open access publication

\begin{abstract}
Uridine adenosine tetraphosphate $\left(\mathrm{Up}_{4} \mathrm{~A}\right)$ exerts potent relaxation in porcine coronary arteries that is reduced following myocardial infarction, suggesting a crucial role for $\mathrm{Up}_{4} \mathrm{~A}$ in the regulation of coronary flow (CF) in cardiovascular disorders. We evaluated the vasoactive effects of $\mathrm{Up}_{4} \mathrm{~A}$ on $\mathrm{CF}$ in atherosclerosis using ApoE knockout (KO) mice ex vivo and in vivo. Functional studies were conducted in isolated mouse hearts using the Langendorff technique. Immunofluorescence was performed to assess purinergic $\mathrm{P} 2 \mathrm{X}_{1}$ receptor $\left(\mathrm{P} 2 \mathrm{X}_{1} \mathrm{R}\right)$ expression in isolated mouse coronary arteries. In vivo effects of $\mathrm{Up}_{4} \mathrm{~A}$ on coronary blood flow (CBF) were assessed using ultrasound. Infusion of $\mathrm{Up}_{4} \mathrm{~A}$ $\left(10^{-9}-10^{-5} \mathrm{M}\right)$ into isolated mouse hearts resulted in a
\end{abstract}

Zhichao Zhou

zhichao.zhou@ki.se

1 Department of Physiology and Pharmacology, Clinical and Translational Science Institute, West Virginia University, Morgantown, WV, USA

2 Present address: Coagulation and Blood Research Task Area, US Army Institute of Surgical Research, San Antonio, TX, USA

3 Present address: Center for Cardiovascular Research and The Heart Center, The Research Institute at Nationwide Children's Hospital, Columbus, OH, USA

4 Present address: Molecular Vascular Medicine, Department of Medicine, Karolinska University Hospital, Karolinska Institutet, Stockholm, Sweden

5 Key Laboratory of Medical Electrophysiology of Ministry of Education, Collaborative Innovation Center for Prevention and Treatment of Cardiovascular Disease, Institute of Cardiovascular Research, Southwest Medical University, Luzhou, China

6 Division of Cardiology, Department of Medicine, Karolinska University Hospital, Karolinska Institutet,

17176 Stockholm, Sweden concentration-dependent reduction in CF in WT and ApoE $\mathrm{KO}$ mice to a similar extent; this effect was exacerbated in ApoE KO mice fed a high-fat diet (HFD). The $\mathrm{P}_{2} \mathrm{X}_{1} \mathrm{R}$ antagonist MRS2159 restored $\mathrm{Up}_{4} \mathrm{~A}$-mediated decreases in $\mathrm{CF}$ more so in ApoE KO + HFD than ApoE KO mice. The smooth muscle to endothelial cell ratio of coronary $\mathrm{P} 2 \mathrm{X}_{1} \mathrm{R}$ expression was greater in ApoE KO + HFD than ApoE KO or WT mice, suggesting a net vasoconstrictor potential of $\mathrm{P} 2 \mathrm{X}_{1} \mathrm{R}$ in ApoE $\mathrm{KO}+\mathrm{HFD}$ mice. In contrast, $\mathrm{Up}_{4} \mathrm{~A}$ $(1.6 \mathrm{mg} / \mathrm{kg})$ increased $\mathrm{CBF}$ to a similar extent among the three groups. In conclusion, $\mathrm{Up}_{4} \mathrm{~A}$ decreases $\mathrm{CF}$ more in $\mathrm{ApoE}$ $\mathrm{KO}+\mathrm{HFD}$ mice, likely through a net upregulation of vasoconstrictor $\mathrm{P} 2 \mathrm{X}_{1} \mathrm{R}$. In contrast, $\mathrm{Up}_{4} \mathrm{~A}$ increases $\mathrm{CBF}$ in vivo regardless of the atherosclerotic model.

Keywords $\mathrm{Up}_{4} \mathrm{~A} \cdot$ Atherosclerosis $\cdot$ Coronary flow $\cdot \mathrm{P} 2 \mathrm{X}_{1} \mathrm{R}$. Vasoconstriction

\section{Introduction}

Ischemic heart disease is characterized by the development of coronary atherosclerosis and is one of the leading causes of death worldwide $[1,2]$. The danger of atherosclerosis is thromboembolism, which evolves from atherosclerotic plaques or thrombotic vessel occlusion and can lead to cardiac ischemia and infarction [2]. Subsequent tissue damage increases the release of extracellular nucleotides and nucleosides, which activate and alter purinergic signaling [3]. Pharmacological interventions using ATP, adenosine, and, more commonly, the purinergic $\mathrm{P} 2 \mathrm{Y}_{12}$ receptor antagonist clopidogrel, have been used for treating patients with coronary artery disease [4].

Uridine adenosine tetraphosphate $\left(\mathrm{Up}_{4} \mathrm{~A}\right)$ was identified as a novel vasoactive factor endogenously released from the endothelium $[5,6]$. $\mathrm{Up}_{4} \mathrm{~A}$ is the first dinucleotide found in living 
organisms that contains both purine and pyrimidine moieties, allowing $\mathrm{Up}_{4} \mathrm{~A}$ to exert its vascular influence through both the purinergic $\mathrm{P} 1$ and $\mathrm{P} 2$ receptors $[6,7]$. Several in vitro studies showed that $\mathrm{Up}_{4} \mathrm{~A}$ induced vascular contraction in rat renal arteries and mouse aortas through the $\mathrm{P} 2 \mathrm{X}_{1}$ receptor $\left(\mathrm{P} 2 \mathrm{X}_{1} \mathrm{R}\right)$ $[5,8,9]$, in rat aortas through the $\mathrm{P} 1$ receptor $(\mathrm{P} 1 \mathrm{R})$ and $\mathrm{P} 2 \mathrm{X}$ receptor $(\mathrm{P} 2 \mathrm{XR})[10]$, and in rat pulmonary arteries through the P2Y receptor (P2YR) [11]. Vasoconstriction was also observed in renal arterioles [12] and rat mesenteric arteries [13]. In contrast to vasoconstrictor influence, $\mathrm{Up}_{4} \mathrm{~A}$ produced vascular relaxation in rat aortas [10, 14], rat kidney [15] and porcine coronary microvessels when the tone is elevated [6]. Interestingly, the vascular effects and potency vary from mice to rats within the same type of arterial segments. Thus, $\mathrm{Up}_{4} \mathrm{~A}$ produces a more pronounced contraction in rat aortas compared to mouse aortas at basal tone $[9,10]$, whereas $\mathrm{Up}_{4} \mathrm{~A}$ induces a concentration-dependent relaxation in rat aortas but a potent contraction in mouse aortas when the vessel tone is elevated $[9,10]$. These findings suggest that the vascular effects of $\mathrm{Up}_{4} \mathrm{~A}$ may not only depend on different vascular beds but also on the species studied.

Observations that intra-aortic injection of $\mathrm{Up}_{4} \mathrm{~A}$ increases mean arterial blood pressure in intact animals [5], plasma concentrations of $\mathrm{Up}_{4} \mathrm{~A}$ in juvenile hypertensive subjects were significantly elevated [16], and that the coronary vasodilator response to $\mathrm{Up}_{4} \mathrm{~A}$ was blunted in swine following myocardial infarction [17] suggest a role for $\mathrm{Up}_{4} \mathrm{~A}$ in the pathogenesis of cardiovascular diseases, including the regulation of coronary vasomotor tone. However, the coronary vascular response to $\mathrm{Up}_{4} \mathrm{~A}$ in atherosclerosis has not been explored.

The present study aimed to determine whether the effect of $\mathrm{Up}_{4} \mathrm{~A}$ on coronary flow $(\mathrm{CF})$ is altered in atherosclerosis and to evaluate the possible role of purinergic receptor subtypes using Langendorff-perfused isolated hearts from the ApoE knockout (KO) mice [18]. Since the effect of $\mathrm{Up}_{4} \mathrm{~A}$ on coronary blood flow (CBF) in vivo is still lacking, we also aimed to investigate the effect of $\mathrm{Up}_{4} \mathrm{~A}$ on $\mathrm{CBF}$ in vivo in atherosclerotic mice using Doppler echocardiography.

\section{Methods}

All experimental protocols were performed according to the West Virginia University guidelines and with the approval of the Animal Care and Use Committee.

\section{Animals}

ApoE KO mice with a C57BL/6 background were purchased from The Jackson Laboratory (Bar Harbor, ME, USA) and bred in our animal facility. At 8 weeks of age, one group of ApoE KO mice were fed a high-fat diet (HFD) ( $0.2 \%$ cholesterol, $21.2 \%$ fat, Harlan Teklad, TD88137) for 12 weeks to accelerate atherosclerotic lesion formation. Another group of ApoE KO mice and wild-type (WT) mice (C57BL/6 background) were maintained on a standard laboratory diet. All animals were kept in cages with 12:12 h light/dark cycles with access to water ad libitum. According to our previous findings [19-21], ApoE KO mice with HFD treatment for 12 weeks exhibited more extensive atherosclerotic lesions and greater total cholesterol levels than ApoE KO mice with the standard diet for the same period, the latter of which was significantly more extensive compared to WT mice. Atherosclerotic lesions were also formed in left coronary arteries of ApoE KO + HFD mice (unpublished).

\section{Langendorff-perfused mouse heart preparations}

Mice (20-22 weeks) of either sex were anesthetized with pentobarbital sodium $(50 \mathrm{mg} / \mathrm{kg}$, i.p.). Mice were weighed before hearts were rapidly removed into heparinized $(5 \mathrm{U} / \mathrm{mL})$ icecold Krebs-Henseleit buffer containing (in mM) $119 \mathrm{NaCl}, 11$ glucose, $22 \mathrm{NaHCO}_{3}, 4.7 \mathrm{KCl}, 1.2 \mathrm{KH}_{2} \mathrm{PO}_{4}, 1.2 \mathrm{MgSO}_{4}, 2.5$ $\mathrm{CaCl}_{2}, 2$ pyruvate, and 0.5 EDTA. After removal of the surrounding tissue, the aorta was rapidly cannulated with a 20 gauge, blunt-ended needle, and the heart was continuously perfused with $37{ }^{\circ} \mathrm{C}$ buffer bubbled with $95 \% \mathrm{O}_{2} / 5 \% \mathrm{CO}_{2}$ at a constant perfusion pressure of $80 \mathrm{mmHg}[22,23]$. Subsequently, through an opening in the left atrium, a fluidfilled balloon made of plastic wrap was inserted into the left ventricle across the mitral valve. The balloon was connected to a pressure transducer for continuous measurement of left ventricular developed pressure (LVDP) and heart rate (HR). The heart was then immersed in a water-jacketed perfusate bath maintained at $37{ }^{\circ} \mathrm{C}$. The viability of the hearts was checked by a 15-s occlusion of inflow (a twofold increase). $\mathrm{CF}$ was continuously measured with an ultrasonic flow probe (Transonic Systems, Ithaca, NY, USA) placed in the aortic perfusion line. A PowerLab Chart data acquisition system (AD Instruments, Colorado Springs, CO, USA) was used for data acquisition. Hearts were allowed to equilibrate for $30 \mathrm{~min}$ before starting experimental protocols.

\section{Langendorff experimental protocols}

After equilibrium, baseline CF, HR, and LVDP were measured. $\mathrm{Up}_{4} \mathrm{~A}$ concentration response curves $\left(10^{-9}-10^{-5} \mathrm{M}\right)$ were acquired in perfused hearts from WT, ApoE KO, and ApoE $\mathrm{KO}+\mathrm{HFD}$ mice. Each concentration of $\mathrm{Up}_{4} \mathrm{~A}$ was infused for $5 \mathrm{~min}$, followed by a minimum of $5 \mathrm{~min}$ of perfusion for washout. Since $\mathrm{Up}_{4} \mathrm{~A}$-induced $\mathrm{CF}$ changes in WT mice were comparable to ApoE KO mice, in separate experiments, the $\mathrm{P}_{2} \mathrm{X}_{1} \mathrm{R}$ antagonist MRS2159 (30 $\mu \mathrm{M}$ [24]; SigmaAldrich, St. Louis, MO, USA) was perfused for $15 \mathrm{~min}$ before acquiring $\mathrm{Up}_{4} \mathrm{~A}$ concentration response curves $\left(10^{-8}-10^{-5} \mathrm{M}\right)$ in perfused hearts only from ApoE KO and ApoE KO + HFD 
mice. MRS2159 was continuously infused throughout the entire experiment at a rate of $1 \%$ of the CF through an injection port directly proximal to the aortic cannula using a microinjection pump (Harvard Apparatus, Holliston, MA, USA). Although MRS2159 predominantly blocks $\mathrm{P} 2 \mathrm{X}_{1} \mathrm{R}$ it was designed for, it cannot be excluded entirely that other purinergic receptors were, to some extent, affected. Careful evaluation of selectivity of MRS2159 is necessary to properly interpret the results in the present study. In addition to $\mathrm{P} 2 \mathrm{X}_{1} \mathrm{R}$, evidence showed that MRS2159 affected $\mathrm{P} 2 \mathrm{X}_{2} \mathrm{R}, \mathrm{P} 2 \mathrm{X}_{2 / 3} \mathrm{R}$, and $\mathrm{P} 2 \mathrm{Y}_{1} \mathrm{R}$ in $1321 \mathrm{~N} 1$ cells [25] and $\mathrm{P} 2 \mathrm{X}_{7} \mathrm{R}$ in $1321 \mathrm{~N} 1$ cells and erythrocytes $[25,26]$. However, the information on specificity of MRS2159 at the intact tissue level is currently lacking.

\section{Fluorescence immunostaining for the $P 2 X_{1} R$ in isolated mouse coronary arteries}

Left coronary arteries (70-150 $\mu \mathrm{m})$ from mouse hearts of WT, ApoE KO, and ApoE KO + HFD were isolated and fixed with $2 \%$ ice-cold paraformaldehyde for $30 \mathrm{~min}$, then permeabilized for $10 \mathrm{~min}$ with $0.1 \%$ Triton $\mathrm{X}-100$. The vessels were then blocked with $5 \%$ goat serum for $1 \mathrm{~h}$ before overnight incubation at $4{ }^{\circ} \mathrm{C}$ with rabbit anti-P2X $\mathrm{X}_{1} \mathrm{R}$ (1:300 dilution; Alomone Labs, Israel) antibodies. The specificity of the antibodies has been tested in our previous study where a band of $55 \mathrm{kDa}$ was observed [9]. The vessels were washed for $1 \mathrm{~h}$ with PBS and incubated for $2 \mathrm{~h}$ with PBS buffer containing Alexa 488conjugated goat anti-rabbit secondary antibodies and DRAQ5 (a nuclear stain, $1 \mu \mathrm{M}$; Invitrogen). The vessels were washed again for $1 \mathrm{~h}$ with PBS and mounted on slides for imaging. A Zeiss LSM 510 confocal microscope was used to collect images from two randomly selected vessel areas. Each stack of images was acquired by optical sectioning at successive $x-y$ focal planes with a vertical depth of $1 \mu \mathrm{m}$ using a Zeiss objective (40/1.30, oil DIC, EC Plan-Neofluar, Thormwood, NY, USA) and a $1024 \times 1024$ scanning format. The mean fluorescence intensity (FI) of each stack of regions of interest (ROIs) that covered the area of individual endothelial cells (ECs, determined by the shape of the nucleus that longitudinally oriented along the vessel axis) and smooth muscle cells (SMCs, cells with a nucleus perpendicularly oriented along the vessel axis, Fig. 3a) was quantified using ImageJ. After subtraction of background signal, a mean of the FI averaged from three ROIs of each vessel segment was calculated and was presented in arbitrary units (AU).

\section{In vivo assessment of echocardiography and CBF Doppler measurement}

In vivo echocardiograph assessments in mice were performed in accordance with our previously published methods [27, 28]. Briefly, each mouse was anesthetized in an induction chamber with inhalant isoflurane at $3 \%$ in $100 \%$ oxygen. When fully anesthetized, the mouse was transferred to dorsal recumbency, placed on a heated imaging platform, and maintained at $1-$ $1.25 \%$ isoflurane for the duration of the experiment. A rectal probe was used to monitor the temperature of the mouse. The hair of the mouse chest was carefully removed, and warm electrode gel was applied to the limb leads, allowing for an electrocardiogram and the respiration rate to be recorded during ultrasound imaging. Ultrasound images were acquired using an MS550D transducer (22-55 MHz) on the Vevo2100 Imaging System (Visual Sonics, Toronto, Canada). Placing the transducer to the left of the sternum allowed us to obtain images of the aortic outflow tract, apex of the heart, and left ventricle along its longest axis (i.e., long-axis B-mode images). Once all long-axis B-mode images were attained, the transducer was rotated $90^{\circ}$ to acquire short-axis B-mode images at the mid-papillary muscle level. Afterward, the transducer was moved up until the left coronary artery was visible to measure the size of the vessel. Then, the transducer was rotated back to the long-axis parasternal view with the probe lateralized and the ultrasound beam anteriorly tilted. In this image window, the entire left coronary artery, from the aortic sinus to the distal branch site, could be visualized using color Doppler echocardiography. The course of the left coronary artery was typically parallel to the Doppler beam, which facilitated Doppler measurements without any angle correction. Subsequently, the system was switched to pulse-wave Doppler mode with a gate size of $0.065 \mathrm{~mm}$. CBF signals were identified on the Doppler spectral display by flow toward the probe, peaking in early diastole and then decaying and being minimal during systole as illustrated in Fig. 4a. Bolus injection of $\mathrm{Up}_{4} \mathrm{~A}(0.04 \mathrm{mg} / \mathrm{mouse}$, approximately $1.6 \mathrm{mg} / \mathrm{kg}$ ) was made through the femoral vein. Flow velocity measurements were made at the same vessel site at baseline and during $\mathrm{Up}_{4} \mathrm{~A}$-mediated $\mathrm{CF}$. Measurements were averaged from three consecutive cardiac cycles.

$\mathrm{CBF}$ was calculated using this formula: $\mathrm{Flow}_{\mathrm{CBF}}(\mathrm{mL} /$ $\min )=((\pi / 4) \times D 2 \times \mathrm{VTI} \times \mathrm{HR}) / 1000$ [29] where $D$ is the internal coronary diameter (in $\mathrm{mm}$ ) measured in B-mode ultrasound images, VTI is the velocity-time-integral (in $\mathrm{mm}$ ), or area under the curve of the Doppler blood flow velocity tracing, and $\mathrm{HR}$ is heart rate. Cardiac function and coronary artery size were measured again after the maximal $\mathrm{Up}_{4} \mathrm{~A}$ effect was achieved.

\section{Statistical analysis}

Langendorff baseline data for WT, ApoE KO, and ApoE $\mathrm{KO}+\mathrm{HFD}$ groups were compared using one-way ANOVA followed by post hoc analysis using Bonferroni's test. The $\mathrm{Up}_{4} \mathrm{~A}$ concentration response curves performed during the Langendorff technique among different groups of mice and the effects of drug treatment on concentration response curves of $\mathrm{Up}_{4} \mathrm{~A}$ were analyzed using two-way ANOVA for repeated measures. Since the absolute CF changes proportionally with heart mass, CF was presented as milliliter/minute/gram wet 
heart weight [22]. With regard to imaging, the mean FI of each ROI (including those in both ECs and SMCs) was calculated by subtraction of the background signal, and changes in FI were presented in AU. Image data were analyzed using oneway ANOVA followed by post hoc analysis using Bonferroni's test. Paired $t$ tests were used to compare the $\mathrm{Up}_{4} \mathrm{~A}$ effect on $\mathrm{CBF}$ in vivo in paired conditions. All the data are presented as mean $\pm \mathrm{SEM} ; n$ represents the number of animals unless otherwise indicated. Statistical significance was accepted when $P<0.05$.

\section{Results}

\section{Baseline functional data in isolated WT, ApoE KO, and ApoE KO + HFD mouse hearts}

Table 1 summarizes the baseline data for CF, HR, and LVDP in WT, ApoE KO, and ApoE KO + HFD mice after 30 min of equilibration of isolated hearts. Compared to age-matched ApoE KO or WT groups, ApoE KO + HFD mice exhibited significant increases in $\mathrm{BW}$ and $\mathrm{HW}(P<0.05)$. However, the heart to body weight ratio was not significantly different among the three groups. There were no significant differences in baseline CF, HR, and LVDP among the three groups $(P>0.05$, by one-way ANOVA, Table 1$)$.

Ex vivo effect of $U p_{4} A$ on $C F$ and cardiac function in WT, ApoE, and ApoE + HFD mice

Infusion of $\mathrm{Up}_{4} \mathrm{~A}\left(10^{-9}-10^{-5} \mathrm{M}\right)$ into isolated hearts resulted in a concentration-dependent decrease in CF to a similar extent between WT $(\sim 34 \%$ maximal reduction from baseline at $\left.10^{-5} \mathrm{M} \mathrm{Up}_{4} \mathrm{~A}\right)$ and ApoE KO mice $(\sim 40 \%$ maximal reduction from baseline at $\left.10^{-5} \mathrm{M} \mathrm{Up} \mathrm{p}_{4} \mathrm{~A}\right)$. Notably, $\mathrm{Up}_{4} \mathrm{~A}$ further and significantly decreased $\mathrm{CF}$ in perfused hearts of ApoE $\mathrm{KO}+$ HFD mice ( $\sim 55 \%$ maximal reduction from baseline at $10^{-5} \mathrm{M}$ $\mathrm{Up}_{4} \mathrm{~A}$, Fig. 1a). Likewise, $\mathrm{Up}_{4} \mathrm{~A}$ infusion produced a concentration-dependent decrease in LVDP similarly between WT $\left(\sim 46 \%\right.$ maximal reduction from baseline at $10^{-5} \mathrm{M}$ $\left.\mathrm{Up}_{4} \mathrm{~A}\right)$ and $\mathrm{ApoE} \mathrm{KO}$ mice ( $\sim 48 \%$ maximal reduction from baseline at $\left.10^{-5} \mathrm{M} \mathrm{Up} 4 \mathrm{~A}\right)$, which was further decreased in ApoE KO + HFD mice ( $\sim 66 \%$ maximal reduction from baseline at $10^{-5} \mathrm{M} \mathrm{Up} \mathrm{p}_{4} \mathrm{~A}$, Fig. 1b). Infusion of $\mathrm{Up}_{4} \mathrm{~A}\left(10^{-9}\right.$ $10^{-5} \mathrm{M}$ ) did not affect HR among the three groups (Fig. 1c).

\section{Effect of $P 2 X_{1} R$ antagonism on $\mathrm{Up}_{4} \mathrm{~A}$-mediated decreases in CF in ApoE and ApoE + HFD mice}

Considering that activation of $\mathrm{P} 2 \mathrm{X}_{1} \mathrm{R}$ contributes to $\mathrm{Up}_{4} \mathrm{~A}$ induced vascular contraction in several vascular beds $[5,8]$ and the effects of $\mathrm{Up}_{4} \mathrm{~A}$ on $\mathrm{CF}$ are comparable between WT and ApoE KO mice, the $\mathrm{P}_{2} \mathrm{X}_{1} \mathrm{R}$ antagonist MRS2159 was used to study potential involvement of the vasoconstrictor $\mathrm{P} 2 \mathrm{X}_{1} \mathrm{R}$ in $\mathrm{Up}_{4} \mathrm{~A}$-mediated changes in $\mathrm{CF}$ from ApoE $\mathrm{KO}$ and $\mathrm{ApoE} \mathrm{KO}+\mathrm{HFD}$ groups. $\mathrm{Up}_{4} \mathrm{~A}$-induced decreases in $\mathrm{CF}$ in ApoE KO + HFD mice ( $\triangle \mathrm{AUC}: 19 \pm 4$, Fig. 2a) were significantly restored by MRS1259 to a greater extent than that in ApoE $\mathrm{KO}$ mice ( $\triangle \mathrm{AUC} 8 \pm 2$, Fig. $2 \mathrm{~b} ; P<0.05$ ). This indicates that the greater vasoconstrictor effect of $\mathrm{Up}_{4} \mathrm{~A}$ observed in perfused hearts from ApoE KO + HFD mice is likely through greater activation of $\mathrm{P} 2 \mathrm{X}_{1} \mathrm{R}$.

\section{Immunohistochemistry for $\mathbf{P} 2 \mathrm{X}_{1} \mathrm{R}$ expression in mouse coronary arteries in WT, ApoE, and ApoE + HFD mice}

There is a generally accepted view that activation of purinergic receptors in ECs results in vascular relaxation, while activation of purinergic receptors in SMCs leads to vascular contraction [30]. We hypothesized that there is a greater upregulation of $\mathrm{P} 2 \mathrm{X}_{1} \mathrm{R}$ in SMCs, thereby contributing to further decreases in $\mathrm{CF}$ in response to $\mathrm{Up}_{4} \mathrm{~A}$ in ApoE $\mathrm{KO}+\mathrm{HFD}$ mice. As shown in Fig. 3, coronary small arteries isolated from ApoE $\mathrm{KO}+$ HFD hearts exhibited a marked decrease in $\mathrm{P} 2 \mathrm{X}_{1} \mathrm{R}$ expression in ECs as compared to either ApoE KO or WT mice, while there was no significant difference in $\mathrm{P} 2 \mathrm{X}_{1} \mathrm{R}$ expression in
Table 1 Basal characteristics for isolated perfused mouse hearts

\begin{tabular}{lccc}
\hline & WT $(n=6)$ & ApoE KO $(n=9)$ & ApoE KO + HFD $(n=9)$ \\
\hline Age, week & $22 \pm 0.6$ & $22 \pm 0.5$ & $21 \pm 0.2$ \\
BW, g & $23 \pm 1.3$ & $26 \pm 1.5$ & $29 \pm 1.0^{*}$ \\
HW, mg & $105.4 \pm 4$ & $127.1 \pm 11.4$ & $144.7 \pm 10.3^{*}$ \\
HW/BW, $\%$ & $0.46 \pm 0.02$ & $0.48 \pm 0.03$ & $0.49 \pm 0.03$ \\
CF, ml min $\mathrm{g}^{-1}$ & $16.7 \pm 0.24$ & $17.6 \pm 1.07$ & $15.9 \pm 0.96$ \\
HR, beats min & $356 \pm 12$ & $372 \pm 8$ & $384 \pm 18$ \\
LVDP, mmHg & $132 \pm 17$ & $106 \pm 10$ & $103 \pm 9$ \\
\hline
\end{tabular}

Values are means \pm SEM

$B W$ body weight, $C F$ coronary flow, $H F D$ high-fat diet, $H R$ heart rate, $L V D P$ left ventricle developed pressure, $W T$ wild type

$* P<0.05$ vs. WT or ApoE KO 


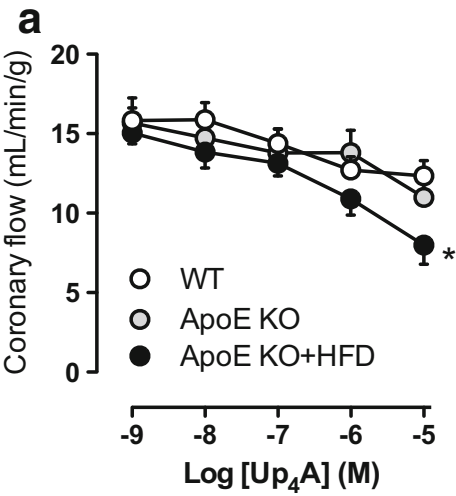

Fig. 1 Effects of $\mathrm{Up}_{4} \mathrm{~A}$ on coronary flow and cardiac function in atherosclerosis. Shown are $\mathrm{Up}_{4} \mathrm{~A}$ concentration responses $\left(10^{-8}-10^{-5}\right.$ M) in isolated hearts of wild-type (WT) $(n=6)$, ApoE knockout (KO) $(n=4)$, and ApoE KO + high-fat diet (HFD) mice $(n=5)$ for coronary

SMCs among the three groups (Fig. 3a, b). Interestingly, the $\mathrm{SMC} / \mathrm{EC}$ ratio of coronary $\mathrm{P} 2 \mathrm{X}_{1} \mathrm{R}$ expression was greater in ApoE KO + HFD than ApoE KO or WT mice (Fig. 3c), suggesting a net vasoconstrictor potential of $\mathrm{P} 2 \mathrm{X}_{1} \mathrm{R}$ in isolated coronary arteries of ApoE KO + HFD mice.

\section{In vivo effect of $\mathrm{Up}_{4} \mathrm{~A}$ on $\mathrm{CBF}$ and cardiac function in $\mathrm{WT}$, ApoE, and ApoE + HFD mice}

To study the in vivo effect of $\mathrm{Up}_{4} \mathrm{~A}$ on $\mathrm{CBF}$, we used Doppler echocardiography to compare changes before and after $\mathrm{Up}_{4} \mathrm{~A}$ bolus injection in anesthetized mice (Fig. 4a: an example of representative tracing for WT). Baseline CBF (expressed in $\mathrm{mL} / \mathrm{min}$ ) was not significantly different among the three groups $(0.27 \pm 0.02$ in WT, $0.37 \pm 0.04$ in ApoE KO, and $0.30 \pm 0.03$ in ApoE KO + HFD; $P>0.05$ by one-way ANOVA; Fig. 4b). Surprisingly, following an injection of $\mathrm{Up}_{4} \mathrm{~A}(1.6 \mathrm{mg} / \mathrm{kg}$, intravenously (i.v.)), $\mathrm{CBF}$ was significantly increased to a similar

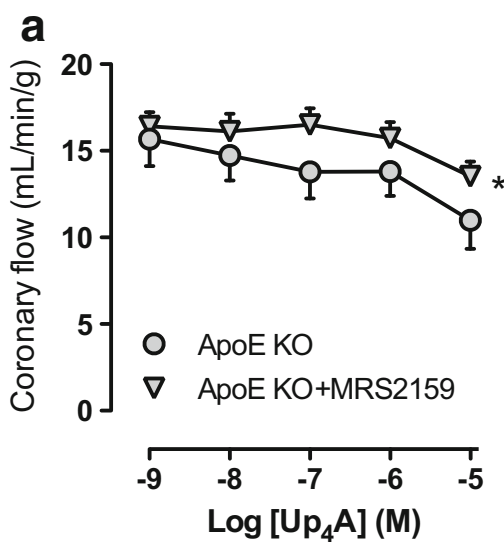

Fig. 2 Effects of $\mathrm{P} 2 \mathrm{X}_{1} \mathrm{R}$ inhibition on $\mathrm{Up}_{4} \mathrm{~A}$-induced decrease in coronary flow in atherosclerosis. Shown are the effects of $P 2 X_{1} R$ antagonist MRS2159 $(30 \mu \mathrm{M})$ on $\mathrm{Up}_{4} \mathrm{~A}$ concentration responses $\left(10^{-8}-10^{-5} \mathrm{M}\right)$ in isolated hearts of ApoE knockout $(\mathrm{KO})(\mathbf{a}, n=4$ in ApoE KO; $n=5$ in ApoE KO + MRS2159) and ApoE KO + high-fat diet

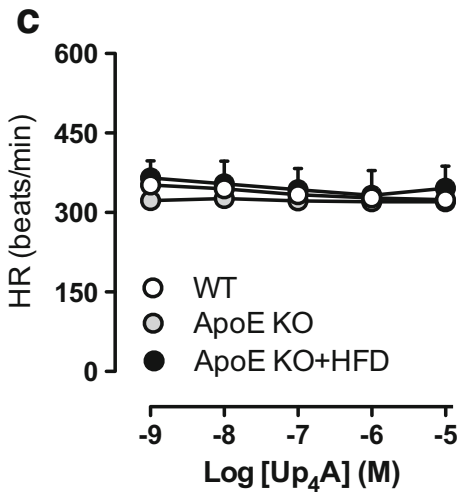

flow (a), left ventricle developed pressure (LVDP, b), and heart rate (HR, c). Values are mean \pm SEM. *Significant difference vs. concentration response curve in WT or ApoE KO by two-way ANOVA $(P<0.05)$

extent among the three groups ( $0.86 \pm 0.11$ in WT, $1.04 \pm 0.19$ in ApoE KO, and $0.91 \pm 0.10$ in ApoE KO + HFD; $P>0.05$ by one-way ANOVA; Fig. 4b). There was no significant difference in baseline HR (Fig. 5a), stroke volume (SV, Fig. 5b), cardiac output (CO, Fig. 5c), and ejection fraction (EF, Fig. $5 d$ ) among the three groups. However, $\mathrm{Up}_{4} \mathrm{~A}$ slightly but significantly increased HR (Fig. 5a), and, to a larger extent, decreased SV (Fig. 5b), which resulted in a significant reduction in CO in WT mice (Fig. 5c), while EF was not affected (Fig. $5 \mathrm{~d})$. There were no significant effects of $\mathrm{Up}_{4} \mathrm{~A}$ on $\mathrm{HR}, \mathrm{SV}, \mathrm{CO}$, and $\mathrm{EF}$ in either ApoE $\mathrm{KO}$ or ApoE KO + HFD mice as compared to corresponding baseline (Fig. $5 \mathrm{a}-\mathrm{d}$ ).

\section{Discussion}

The main findings of the present study are: (1) Infusion of $\mathrm{Up}_{4} \mathrm{~A}$ resulted in reduced $\mathrm{CF}$ in isolated hearts of WT and

b

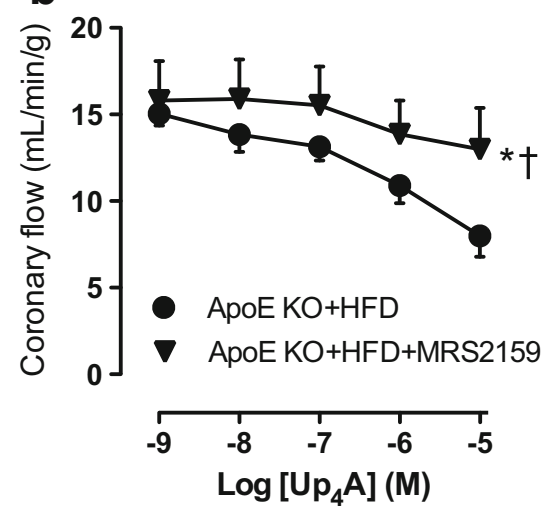

(HFD) mice (b, $n=5$ in ApoE KO + HFD; $n=4$ in ApoE KO + HFD + MRS2159). Values are mean \pm SEM. *Significant difference vs. corresponding control concentration response curve by two-way ANOVA $(P<0.05)$ 
a
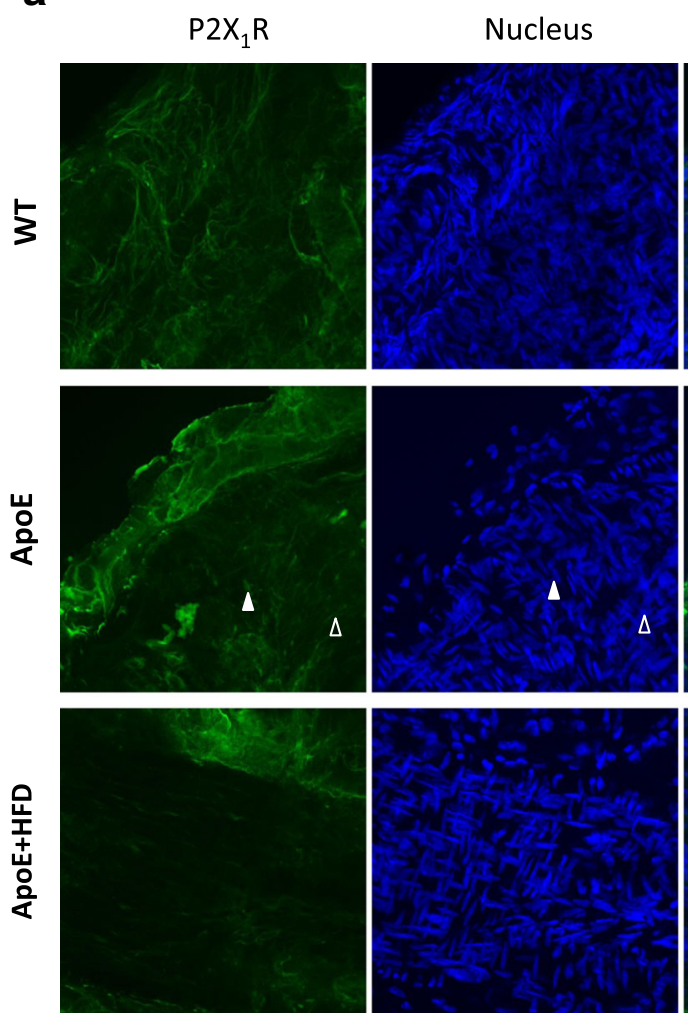

Fig. $3 \mathrm{P}_{2} \mathrm{X}_{1} \mathrm{R}$ expression in isolated mouse coronary arteries in atherosclerosis. a Representative confocal fluorescence images showing $\mathrm{P} 2 \mathrm{X}_{1} \mathrm{R}$ fluorescence intensity in coronary arteries from WT, ApoE knockout (KO), and ApoE KO + high-fat diet (HFD) mice. Scale bar $50 \mu \mathrm{m}$; solid triangle: smooth muscle cells (SMCs) or corresponding nucleus; open triangle: endothelial cells (ECs) or corresponding nucleus.

ApoE $\mathrm{KO}$ mice to a similar extent, while $\mathrm{Up}_{4} \mathrm{~A}$ further decreased CF in ApoE KO + HFD mice; (2) P2 $\mathrm{X}_{1} \mathrm{R}$ antagonism using MRS2159 restored impaired CF in ApoE KO + HFD more than that in ApoE KO mice; (3) The SMC/EC ratio of coronary $\mathrm{P} 2 \mathrm{X}_{1} \mathrm{R}$ expression was greater in ApoE $\mathrm{KO}+\mathrm{HFD}$ than ApoE KO or WT mice; and (4) In contrast, bolus b

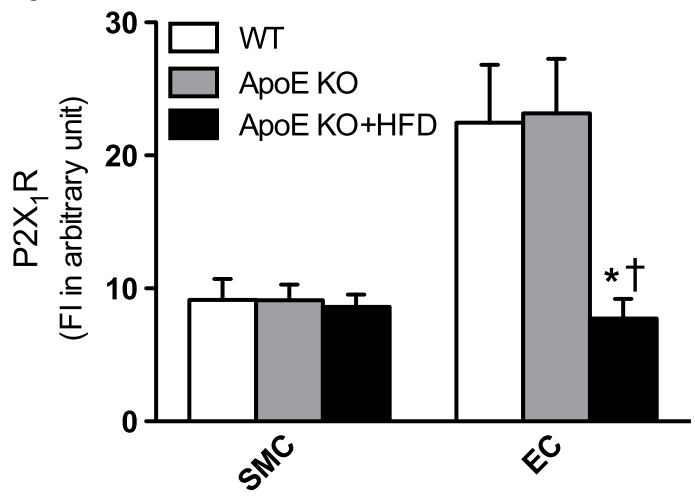

C

$50 \mu \mathrm{m}$

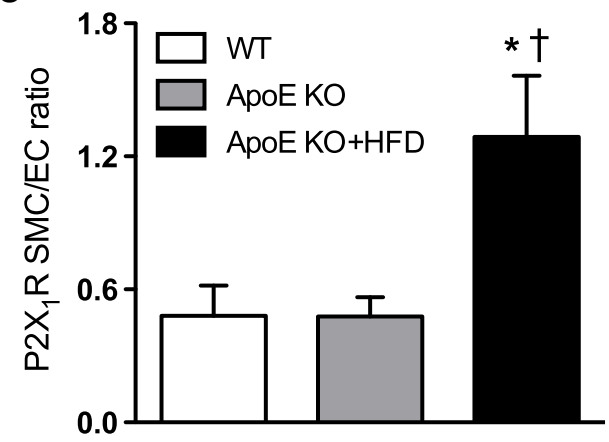

b Quantification of $\mathrm{P} 2 \mathrm{X}_{1} \mathrm{R}$ expression in ECs vs. SMCs in isolated coronary arteries from WT $(n=5), \operatorname{ApoE~KO}(n=9)$, and ApoE KO + HFD mice $(n=5)$. $\mathbf{c ~ S M C / E C ~ r a t i o ~ o f ~} \mathrm{P} 2 \mathrm{X}_{1} \mathrm{R}$ expression in isolated coronary arteries from WT, ApoE KO, and ApoE KO + HFD mice. Values are mean \pm SEM. $* P<0.05$ vs. corresponding WT; $\uparrow P<0.05$ vs. corresponding ApoE KO

injection of $\mathrm{Up}_{4} \mathrm{~A}$ increased $\mathrm{CBF}$ in vivo to a similar extent among the three groups. The implications of these findings are discussed below.

$\mathrm{Up}_{4} \mathrm{~A}$ was first identified as a potent endothelium-derived vasoconstrictor in rat perfused kidney [5]. Several subsequent studies have confirmed that $\mathrm{Up}_{4} \mathrm{~A}$ produces vasoconstriction

Fig. 4 Effects of $\mathrm{Up}_{4} \mathrm{~A}$ on coronary blood flow $(\mathrm{CBF})$ in vivo in atherosclerosis. Shown are effects of bolus $\mathrm{Up}_{4} \mathrm{~A}$ intravenous injection on $\mathrm{CBF}$ in $\mathrm{WT}$ $(n=5)$, ApoE knockout $(\mathrm{KO}$, $n=3$ ), and ApoE KO + high-fat diet (HFD) mice $(n=5)$. a Representative tracing for WT. b Quantification of baseline CBF and increase in $\mathrm{CBF}$ to a single dose of $\mathrm{Up}_{4} \mathrm{~A}$. Values are mean \pm SEM. $* P<0.05$ vs. corresponding baseline a
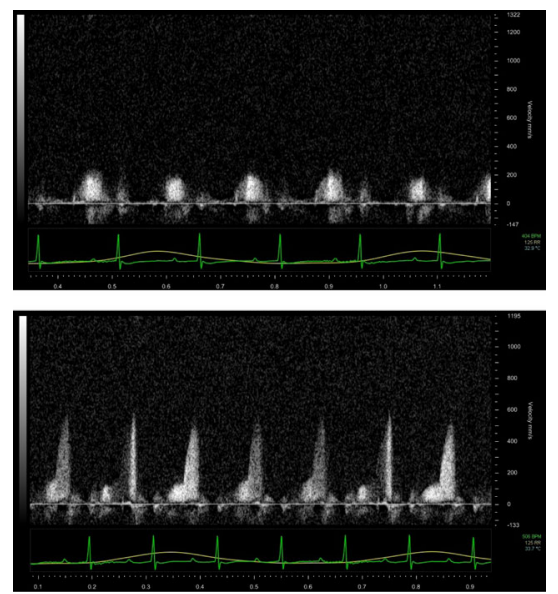

b

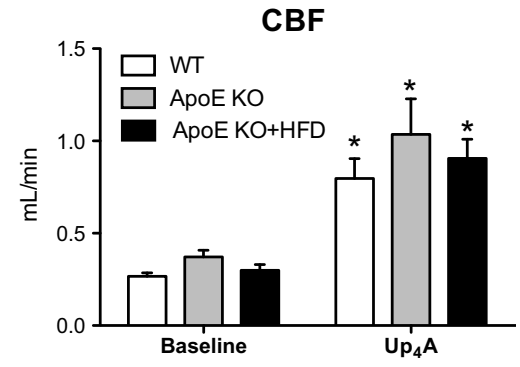


Fig. 5 Effects of $\mathrm{Up}_{4} \mathrm{~A}$ on cardiac function in vivo in atherosclerosis. Shown are effects of bolus $\mathrm{Up}_{4} \mathrm{~A}$ intravenous injection on heart rate $(\mathrm{HR}, \mathbf{a})$, stroke volume (SV, b), cardiac output $(\mathrm{CO}, \mathbf{c})$, and ejection fraction (EF, d) in WT $(n=5)$, ApoE knockout (KO, $n=3)$, and ApoE KO + high-fat diet (HFD) mice $(n=5)$. Values are mean \pm SEM. $* P<0.05$ vs. corresponding baseline
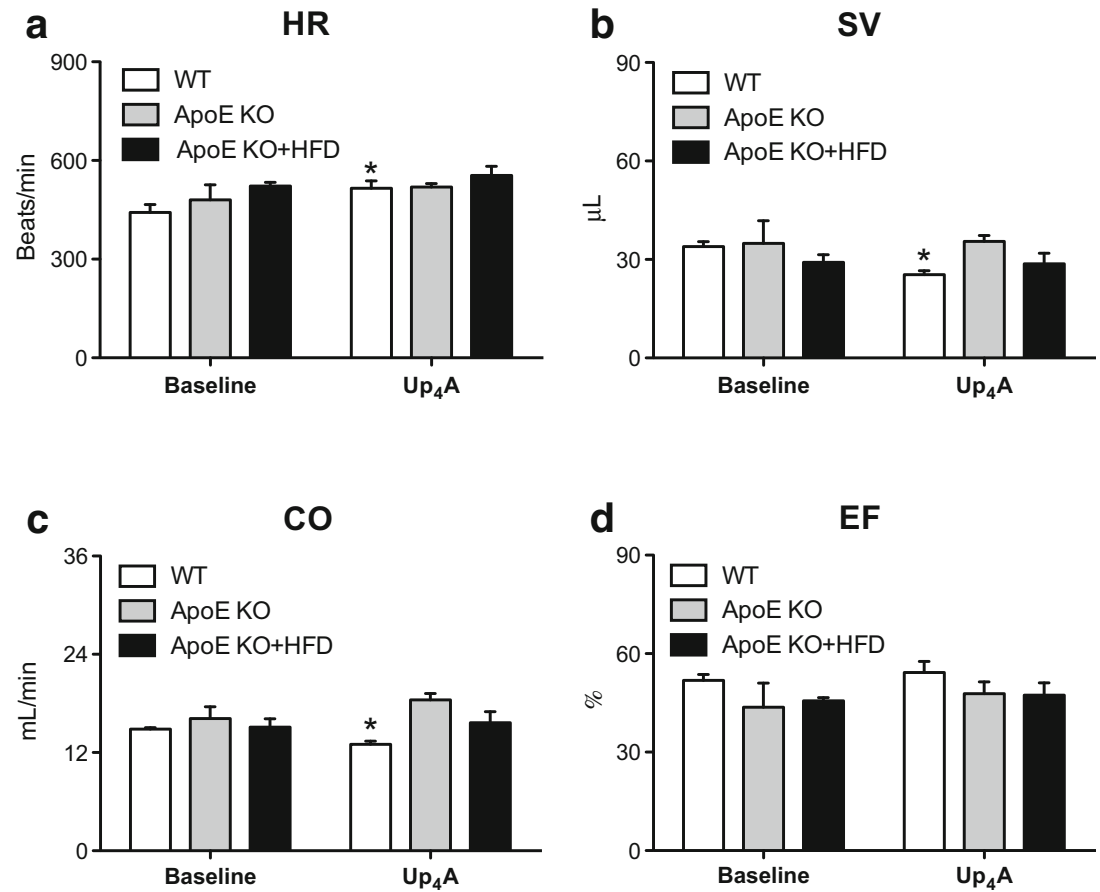

in rat renal arteries [31], aortas [10], gastric smooth muscle [32], and pulmonary arteries [11]. Furthermore, vasoconstriction was observed in mouse renal arterioles [12] and aortas [8]. On the other hand, there is evidence that $\mathrm{Up}_{4} \mathrm{~A}$ can produce relaxation in isolated aortic rings of rats [10], rat kidney [15], and human and mouse colon [33]. Interestingly, the vascular effects or potency vary from mice to rats within the same type of arterial segments. Thus, $\mathrm{Up}_{4} \mathrm{~A}$ produces a more pronounced contraction in rat aortas as compared to mouse aortas at basal tone $[9,10]$, whereas $\mathrm{Up}_{4} \mathrm{~A}$ induces a concentrationdependent relaxation in rat aortas but produces a potent contraction in mouse aortas when the vessel tone is elevated [9, 10]. All these findings suggest that the vascular effects of $\mathrm{Up}_{4} \mathrm{~A}$ may not only depend on different vascular beds but also different species studied [7]. In contrast to vasodilator effect of $\mathrm{Up}_{4} \mathrm{~A}$ in porcine coronary small arteries (non-resistance vessel with diameter of $\sim 250 \mu \mathrm{m}$ ) [6], infusion of $\mathrm{Up}_{4} \mathrm{~A}$ into isolated mouse hearts (coronary resistance vessel) resulted in a concentration-dependent decrease in CF. Moreover, $\mathrm{Up}_{4} \mathrm{~A}$ produces a mild contraction in isolated coronary arteries of mice (conduit arteries with diameter of $\sim 100 \mu \mathrm{m}$; data not shown) further supporting the notion that $\mathrm{Up}_{4} \mathrm{~A}$-induced coronary vascular effect is species-dependent. Future studies are needed to explore the vascular effect of $\mathrm{Up}_{4} \mathrm{~A}$ in human coronary arteries with a similar diameter setting.

We and others have previously demonstrated altered purinergic signaling in coronary microcirculation in atherosclerotic/-like animal models. Thus, ATP increases $\mathrm{CBF}$, which is reduced in ApoE $\mathrm{KO}$ mice, likely via decreased activation of $\mathrm{P} 2 \mathrm{Y}_{2} \mathrm{R}$ [34]. $\mathrm{A}_{2 \mathrm{~A}} \mathrm{R}$ agonist increases $\mathrm{CF}$ in both
ApoE $\mathrm{KO}$ and ApoE $\mathrm{KO}+\mathrm{HFD}$ mice through increased activation of $\mathrm{A}_{2 \mathrm{~A}} \mathrm{R}$ [19], while coronary reactive hyperemia is impaired in female ApoE KO + HFD as compared to WT mice, suggesting a compensatory mechanism for adenosine receptor-mediated coronary microvascular regulation in atherosclerosis [20]. Moreover, although coronary vasodilation is not altered in response to adenosine receptor stimulation, $\mathrm{A}_{2 \mathrm{~B}} \mathrm{R}$ is downregulated in coronary arterioles of swine with early-stagy metabolic syndrome [35]. P1Rs are the major purinergic receptors involved in $\mathrm{Up}_{4} \mathrm{~A}$-mediated coronary relaxation in swine. $\mathrm{Up}_{4} \mathrm{~A}$-induced coronary relaxation is blunted in swine following myocardial infarction, likely through downregulation of $\mathrm{A}_{2 \mathrm{~B}} \mathrm{R}$ [17]. In the present study, infusion of $\mathrm{Up}_{4} \mathrm{~A}$ into isolated mouse hearts resulted in a comparable reduction in $\mathrm{CF}$ between ApoE $\mathrm{KO}$ and WT mice, while $\mathrm{Up}_{4} \mathrm{~A}$ further decreased $\mathrm{CF}$ in ApoE KO + HFD mice (Fig. 1a). The further decrease in CF in ApoE KO + HDF mice was possibly through increased activation of $\mathrm{P} 2 \mathrm{X}_{1} \mathrm{R}$, as evidenced by the rescue of $\mathrm{P} 2 \mathrm{X}_{1} \mathrm{R}$ antagonism on $\mathrm{CF}$ is higher in ApoE KO + HFD as compared to ApoE KO mice (Fig. 2). Additionally, the comparable reduction in $\mathrm{CF}$ response to $\mathrm{Up}_{4} \mathrm{~A}$ between WT and ApoE KO mice and further decrease in $\mathrm{CF}$ in ApoE $\mathrm{KO}+\mathrm{HFD}$ are supported by a similar $\mathrm{P} 2 \mathrm{X}_{1} \mathrm{R}$ expression pattern in the coronary arteries of mice (Fig. 3); particularly, $\mathrm{P} 2 \mathrm{X}_{1} \mathrm{R}$ is proposed to be more abundantly expressed in arterioles [36]. Thus, no differences in coronary $\mathrm{P} 2 \mathrm{X}_{1} \mathrm{R}$ expression in ECs between ApoE KO and WT mice were noted; $\mathrm{P} 2 \mathrm{X}_{1} \mathrm{R}$ expression in ECs was markedly decreased in ApoE KO + HFD mice. The $\mathrm{P}_{2} \mathrm{X}_{1} \mathrm{R}$ expression in SMCs of mouse coronary arteries is similar among the three 
groups. It is generally accepted that activation of $\mathrm{P} 2$ receptor subtypes in ECs leads to vasodilation while activation of P2 receptor subtypes in SMCs results in vasoconstriction [30]. Interestingly, the SMC/EC ratio of coronary $\mathrm{P} 2 \mathrm{X}_{1} \mathrm{R}$ expression was greater in ApoE KO + HFD than ApoE KO or WT mice (Fig. 3c), suggesting a greater net vasoconstrictor potential of $\mathrm{P} 2 \mathrm{X}_{1} \mathrm{R}$ in isolated coronary arteries of $\mathrm{ApoE} \mathrm{KO}+$ HFD mice, contributing to a further reduction in CF in response to $\mathrm{Up}_{4} \mathrm{~A}$. The alteration of $\mathrm{P} 2 \mathrm{X}_{1} \mathrm{R}$ expression in $\mathrm{ECs}$ but not SMCs is likely due to influence of atherosclerotic lesions in coronary vasculature in our ApoE KO + HFD mice [37]. Future studies are needed to confirm this issue. Interestingly, we previously demonstrated that an endothelial dysfunction (evaluated by A23187 concentration responseinduced nitric oxide-dependent flow increase and reactive hyperemia) exists in coronary microcirculation in female but not in male ApoE KO + HFD mice, while sodium nitroprussideinduced increase in coronary flow is comparable between WT and ApoE KO + HFD groups in both sexes [20]. In isolated hearts from male mice of the present study, $\mathrm{Up}_{4} \mathrm{~A}$ still further decreased coronary flow in ApoE KO + HFD compared to WT mice (Emax $13.4 \pm 0.8 \mathrm{~mL} / \mathrm{min} / \mathrm{g}$ in WT vs. $6.0 \pm 0.8 \mathrm{~mL} /$ $\mathrm{min} / \mathrm{g}$ in ApoE KO + HFD; $P<0.05$ by two-way ANOVA, $n=3$ ), suggesting $\mathrm{Up}_{4} \mathrm{~A}$-induced decrease in coronary flow is likely direct rather than via an indirect effect of endothelial dysfunction.

Together with the functional role of $\mathrm{P} 2 \mathrm{X}_{1} \mathrm{R}$ in $\mathrm{Up}_{4} \mathrm{~A}$-mediated vasoconstriction in perfused rat/mouse kidney $[5,12]$ and isolated mouse aortas [8], this evidence suggests that there is likely a similar activation of $\mathrm{P} 2 \mathrm{X}_{1} \mathrm{R}$ in $\mathrm{Up}_{4} \mathrm{~A}$-induced decreases in CF in WT mice as compared to ApoE KO mice. We previously showed that more excessive atherosclerotic lesions and greater total cholesterol levels were present in ApoE $\mathrm{KO}+$ HFD mice, followed by ApoE KO mice when compared to WT mice [19-21]. Moreover, coronary atherosclerotic lesions were formed in left coronary arteries of ApoE KO + HFD mice (unpublished). However, $\mathrm{CF}$ in response to $\mathrm{Up}_{4} \mathrm{~A}$ and coronary $\mathrm{P} 2 \mathrm{X}_{1} \mathrm{R}$ expression are apparently not affected by more excessive atherosclerotic lesions and greater total cholesterol conditions in ApoE KO mice as compared to WT mice (Figs. 1a and 3). The further reduction in $\mathrm{CF}$ induced by $\mathrm{Up}_{4} \mathrm{~A}$, as well as upregulation of the net vasoconstrictor $\mathrm{P}_{2} \mathrm{X}_{1} \mathrm{R}$ in ApoE $\mathrm{KO}+$ HFD mice, may be due to advanced atherosclerosis. In line with this concept, several P2XRs including $\mathrm{P}_{2} \mathrm{X}_{1}$ Rs are upregulated in bladder tissue that underwent atherosclerosis-induced ischemia [38]. This implies a crucial role for $\mathrm{P} 2 \mathrm{X}_{1} \mathrm{R}$ in an advanced atherosclerotic model.

The in vivo effect of $\mathrm{Up}_{4} \mathrm{~A}$ has been shown by Hansen et al., where i.v. infusion of $\mathrm{Up}_{4} \mathrm{~A}(512 \mathrm{nmol} / \mathrm{kg} / \mathrm{min})$ into conscious mice [14] induces hypotension, suggesting a vasodilator influence of $\mathrm{Up}_{4} \mathrm{~A}$ on systemic circulation. The $\mathrm{Up}_{4} \mathrm{~A}$ induced systemic vasodilation is direct, rather than indirect, through degraded product (e.g., adenosine) and contradictory to vasoconstrictor effects observed in most isolated arteries from systemic vascular beds [7]. In the present study, bolus injection of $\mathrm{Up}_{4} \mathrm{~A}$ resulted in more than a twofold increase in $\mathrm{CBF}$ as compared to baseline in WT mice (Fig. 4a, b), which was similar to ApoE KO or ApoE KO + HFD groups. The dose of $\mathrm{Up}_{4} \mathrm{~A}(1.6 \mathrm{mg} / \mathrm{kg} \approx 40 \mu \mathrm{g} / \mathrm{animal})$ used in the present study was much higher than that used in the study by Hansen et al. ( $512 \mathrm{nmol} / \mathrm{kg} / \mathrm{min} \approx 0.3 \mu \mathrm{g} / \mathrm{animal})$ [14]; thus, i.v. injection of such high dose $\mathrm{Up}_{4} \mathrm{~A}$ possibly induces systemic vasodilation and hypotension. This may result in an increase in HR and decreases in SV and CO in WT mice observed in the present study.

The different effects of $\mathrm{Up}_{4} \mathrm{~A}$ on $\mathrm{CF}$ between ex vivo and in vivo cannot be readily explained. The in vivo system is much more complex compared to isolated hearts in which there is no influence of hormone, nerves, blood flow, and blood components. The increase in $\mathrm{HR}$ in response to $\mathrm{Up}_{4} \mathrm{~A}$ in WT mice may increase metabolic demand, leading to increases in CBF. However, the changes in cardiac function induced by $\mathrm{Up}_{4} \mathrm{~A}$ observed in WT mice are not present in ApoE KO or ApoE KO + HFD mice (Fig. 5), while the increase in CBF is comparable among the three groups (Fig. 5b), suggesting that the changes in metabolic demand unlikely account for the increased CBF. Another explanation is that the vasodilator effect of $\mathrm{Up}_{4} \mathrm{~A}$ on coronary circulation is indirectly through nucleotidase-breakdown products, e.g., ATP, as activity of nucleotidase such as ATPase and ADPase in aortas of ApoE KO mice is altered [34]. However, Hansen et al. proposed that degradation of $\mathrm{Up}_{4} \mathrm{~A}$ is unlikely by continual infusion into systemic circulation [14]. The net vasodilator effect of $\mathrm{Up}_{4} \mathrm{~A}$ observed in vivo may be due to the indirect vasodilator effects from $\mathrm{Up}_{4} \mathrm{~A}$-activated vasodilator purinergic receptors in non-vessel tissues (e.g., erythrocyte) overweighing the direct vasoconstrictor effects from $\mathrm{Up}_{4} \mathrm{~A}-$ activated vasoconstrictor purinergic receptors in coronary vasculature. As mentioned earlier that the dose of $\mathrm{Up}_{4} \mathrm{~A}$ used in the present study is high, the $\mathrm{Up}_{4} \mathrm{~A}$-induced increase in $\mathrm{CBF}$ may, however, still not plateaued as compared to a greater coronary vasodilation induced by adenosine in mice from previous studies of ours [28] and others [39]. This may explain why the increases in $\mathrm{CBF}$ in response to $\mathrm{Up}_{4} \mathrm{~A}$ among WT, ApoE KO, and ApoE KO + HFD groups are not significantly different.

In conclusion, the present findings demonstrate that there are divergent vascular effects of $\mathrm{Up}_{4} \mathrm{~A}$ on coronary microcirculation between ex vivo and in vivo in mice. $\mathrm{Up}_{4} \mathrm{~A}$ directly decreases $\mathrm{CF}$, possibly through $\mathrm{P} 2 \mathrm{X}_{1} \mathrm{R}$, which is further reduced via greater downregulation of the vasodilator $\mathrm{P}_{2} \mathrm{X}_{1} \mathrm{R}$ in ECs in ApoE KO + HFD mice. In contrast, $\mathrm{Up}_{4} \mathrm{~A}$ increases $\mathrm{CBF}$ in vivo regardless of the atherosclerotic model. Based on the dysregulation of $\mathrm{P} 2 \mathrm{X}_{1} \mathrm{R}$ in coronary microvasculature in atherosclerosis, $\mathrm{P} 2 \mathrm{X}_{1} \mathrm{R}$ may serve as a potential therapeutic target for the treatment of ischemic heart disease. 
Acknowledgements This study was supported by the National Institutes of Health grant HL 027339 and U54GM104942 (to SJ Mustafa), the Southwest Medical University China grant MEPSCKL201301 (to Z Zhou), the Olausson Fund from Thorax of Karolinska University Hospital (to Z Zhou), and the Karolinska Institutet grant (to Z Zhou). The authors thank Dr. Brandi Talkington for editorial support. The content is solely the responsibility of the authors and does not necessarily represent the official views of the NIH.

Compliance with ethical standards All experimental protocols were performed according to the West Virginia University guidelines and with the approval of the Animal Care and Use Committee.

Conflict of interest Bunyen Teng declares that he/she has no conflict of interest.

Hicham Labazi declares that she has no conflict of interest. Changyan Sun declares that she has no conflict of interest. Yan Yang declares that she has no conflict of interest.

Xiaorong Zeng declares that she has no conflict of interest. S. Jamal Mustafa declares that he has no conflict of interest. Zhichao Zhou declares that he has no conflict of interest.

Open Access This article is distributed under the terms of the Creative Commons Attribution 4.0 International License (http:// creativecommons.org/licenses/by/4.0/), which permits unrestricted use, distribution, and reproduction in any medium, provided you give appropriate credit to the original author(s) and the source, provide a link to the Creative Commons license, and indicate if changes were made.

\section{References}

1. Panza JA (2010) Coronary atherosclerosis: extending to the microcirculation? Eur Heart J 31(8):905-907. doi:10.1093/eurheartj/ ehq044

2. Marzilli M, Merz CN, Boden WE, Bonow RO, Capozza PG, Chilian WM, DeMaria AN, Guarini G, Huqi A, Morrone D, Patel MR, Weintraub WS (2012) Obstructive coronary atherosclerosis and ischemic heart disease: an elusive link! J Am Coll Cardiol 60(11):951-956. doi:10.1016/j.jacc.2012.02.082

3. Burnstock $G$ (2017) Purinergic signaling in the cardiovascular system. Circ Res 120(1):207-228. doi:10.1161/CIRCRESAHA.116. 309726

4. Burnstock G, Ralevic V (2014) Purinergic signaling and blood vessels in health and disease. Pharmacol Rev 66(1):102-192. doi: 10.1124/pr.113.008029

5. Jankowski V, Tolle M, Vanholder R, Schonfelder G, van der Giet M, Henning L, Schluter H, Paul M, Zidek W, Jankowski J (2005) Uridine adenosine tetraphosphate: a novel endothelium-derived vasoconstrictive factor. Nat Med 11(2):223-227. doi:10.1038/ nm1188

6. Zhou Z, Merkus D, Cheng C, Duckers HJ, Jan Danser AH, Duncker DJ (2013) Uridine adenosine tetraphosphate is a novel vasodilator in the coronary microcirculation which acts through purinergic P1 but not P2 receptors. Pharmacol Res 67(1):10-17. doi:10.1016/j.phrs.2012.09.011

7. Matsumoto T, Tostes RC, Webb RC (2011) The role of uridine adenosine tetraphosphate in the vascular system. Adv Pharmacol Sci 2011:435132. doi:10.1155/2011/435132

8. Zhou Z, Sun C, Tilley SL, Mustafa SJ (2015) Mechanisms underlying uridine adenosine tetraphosphate-induced vascular contraction in mouse aorta: role of thromboxane and purinergic receptors. Vasc Pharmacol 73:78-85. doi:10.1016/j.vph.2015.04. 009

9. Zhou Z, Yadav VR, Sun C, Teng B, Mustafa JS (2016) Impaired aortic contractility to Uridine adenosine tetraphosphate in angiotensin II-induced hypertensive mice: receptor desensitization? Am J Hypertens. doi:10.1093/ajh/hpw163

10. Linder AE, Tumbri M, Linder FF, Webb RC, Leite R (2008) Uridine adenosine tetraphosphate induces contraction and relaxation in rat aorta. Vasc Pharmacol 48(4-6):202-207. doi:10.1016/j. vph.2008.03.003

11. Gui Y, Walsh MP, Jankowski V, Jankowski J, Zheng XL (2008) Up4A stimulates endothelium-independent contraction of isolated rat pulmonary artery. Am J Pysiol Lung Cell Mol Physiol 294(4): L733-L738. doi:10.1152/ajplung.00403.2007

12. Jankowski V, Patzak A, Herget-Rosenthal S, Tran TN, Lai EY, Gunthner T, Buschmann I, Zidek W, Jankowski J (2008) Uridine adenosine tetraphosphate acts as an autocrine hormone affecting glomerular filtration rate. J Mol Med (Berl) 86(3):333-340. doi: 10.1007/s00109-008-0306-6

13. Matsumoto T, Tostes RC, Webb RC (2012) Alterations in vasoconstrictor responses to the endothelium-derived contracting factor uridine adenosine tetraphosphate are region specific in DOCA-salt hypertensive rats. Pharmacol Res 65(1):81-90. doi:10.1016/j.phrs. 2011.09.005

14. Hansen PB, Hristovska A, Wolff H, Vanhoutte P, Jensen BL, Bie P (2010) Uridine adenosine tetraphosphate affects contractility of mouse aorta and decreases blood pressure in conscious rats and mice. Acta Physiol (Oxf) 200(2):171-179. doi:10.1111/j.17481716.2010.02135.x

15. Tolle M, Schuchardt M, Wiedon A, Huang T, Klockel L, Jankowski J, Jankowski V, Zidek W, van der Giet M (2010) Differential effects of uridine adenosine tetraphosphate on purinoceptors in the rat isolated perfused kidney. Br J Pharmacol 161(3):530-540. doi:10. 1111/j.1476-5381.2010.00914.x

16. Jankowski V, Meyer AA, Schlattmann P, Gui Y, Zheng XL, Stamcou I, Radtke K, Tran TN, van der Giet M, Tolle M, Zidek W, Jankowski J (2007) Increased uridine adenosine tetraphosphate concentrations in plasma of juvenile hypertensives. Arterioscler Thromb Vasc Biol 27(8):1776-1781. doi:10.1161/ATVBAHA. 107.143958

17. Zhou Z, de Wijs-Meijler D, Lankhuizen I, Jankowski J, Jankowski V, Jan Danser AH, Duncker DJ, Merkus D (2013) Blunted coronary vasodilator response to uridine adenosine tetraphosphate in postinfarct remodeled myocardium is due to reduced P1 receptor activation. Pharmacol Res 77:22-29. doi:10.1016/j.phrs.2013.08.007

18. Meir KS, Leitersdorf E (2004) Atherosclerosis in the apolipoprotein-E-deficient mouse: a decade of progress. Arterioscler Thromb Vasc Biol 24(6):1006-1014. doi:10.1161/ 01.ATV.0000128849.12617.f4

19. Teng B, Mustafa SJ (2011) A(2A) adenosine receptor-mediated increase in coronary flow in hyperlipidemic APOE-knockout mice. J Exp Pharmacol 2011(3):59-68. doi:10.2147/JEP.S18945

20. Zhou X, Teng B, Mustafa SJ (2015) Sex difference in coronary endothelial dysfunction in apolipoprotein $\mathrm{E}$ knockout mouse: role of NO and A2A adenosine receptor. Microcirculation 22(7):518 527. doi: $10.1111 /$ micc. 12222

21. Teng B, Smith JD, Rosenfeld ME, Robinet P, Davis ME, Morrison RR, Mustafa SJ (2014) A(1) adenosine receptor deficiency or inhibition reduces atherosclerotic lesions in apolipoprotein $\mathrm{E}$ deficient mice. Cardiovasc Res 102(1):157-165. doi:10.1093/cvr/cvu033

22. Zhou Z, Rajamani U, Labazi H, Tilley SL, Ledent C, Teng B, Mustafa SJ (2015) Involvement of NADPH oxidase in A2A adenosine receptor-mediated increase in coronary flow in isolated mouse hearts. Purinergic Signal 11(2):263-273. doi:10.1007/ s11302-015-9451-x 
23. Teng B, Ledent C, Mustafa SJ (2008) Up-regulation of A 2B adenosine receptor in A 2A adenosine receptor knockout mouse coronary artery. J Mol Cell Cardiol 44(5):905-914. doi:10.1016/j. yjmcc.2008.03.003

24. Wee S, Peart JN, Headrick JP (2007) P2 purinoceptor-mediated cardioprotection in ischemic-reperfused mouse heart. J Pharmacol Exp Ther 323(3):861-867. doi:10.1124/jpet.107.125815

25. Donnelly-Roberts DL, Namovic MT, Han P, Jarvis MF (2009) Mammalian P2X7 receptor pharmacology: comparison of recombinant mouse, rat and human $\mathrm{P} 2 \mathrm{X} 7$ receptors. Br J Pharmacol 157(7):1203-1214. doi:10.1111/j.1476-5381.2009.00233.x

26. Sophocleous RA, Mullany PR, Winter KM, Marks DC, Sluyter R (2015) Propensity of red blood cells to undergo P2X7 receptormediated phosphatidylserine exposure does not alter during in vivo or ex vivo aging. Transfusion 55(8):1946-1954. doi:10. $1111 /$ trf. 13101

27. Labazi H, Teng B, Zhou Z, Mustafa SJ (2016) Enhanced A2A adenosine receptor-mediated increase in coronary flow in type I diabetic mice. J Mol Cell Cardiol 90:30-37. doi:10.1016/j.yjmcc. 2015.11.033

28. Teng B, Tilley SL, Ledent C, Mustafa SJ (2016) In vivo assessment of coronary flow and cardiac function after bolus adenosine injection in adenosine receptor knockout mice Physiol Rep 4 (11). Doi: $10.14814 /$ phy 2.12818

29. Katz PS, Trask AJ, Souza-Smith FM, Hutchinson KR, Galantowicz ML, Lord KC, Stewart JA Jr, Cismowski MJ, Varner KJ, Lucchesi PA (2011) Coronary arterioles in type 2 diabetic $(\mathrm{db} / \mathrm{db})$ mice undergo a distinct pattern of remodeling associated with decreased vessel stiffness. Basic Res Cardiol 106(6):1123-1134. doi:10. 1007/s00395-011-0201-0

30. Burnstock $\mathrm{G}$ (2010) Control of vascular tone by purines and pyrimidines. Br J Pharmacol 161(3):527-529. doi:10.1111/j.1476-5381. 2010.00937.x

31. Matsumoto T, Tostes RC, Webb RC (2011) Uridine adenosine tetraphosphate-induced contraction is increased in renal but not pulmonary arteries from DOCA-salt hypertensive rats. Am J
Physiol Heart Circ Physiol 301(2):H409-H417. doi:10.1152/ ajpheart.00084.2011

32. Yuan W, Wang Z, Li J, Li D, Liu D, Bai G, Walsh MP, Gui Y, Zheng XL (2013) Uridine adenosine tetraphosphate induces contraction of circular and longitudinal gastric smooth muscle by distinct signaling pathways. IUBMB Life 65(7):623-632. doi:10.1002/iub.1171

33. Durnin L, Hwang SJ, Kurahashi M, Drumm BT, Ward SM, Sasse KC, Sanders KM, Mutafova-Yambolieva VN (2014) Uridine adenosine tetraphosphate is a novel neurogenic P2Y1 receptor activator in the gut. Proc Natl Acad Sci U S A 111(44):15821-15826. doi:10. 1073/pnas.1409078111

34. Mercier N, Kiviniemi TO, Saraste A, Miiluniemi M, Silvola J, Jalkanen S, Yegutkin GG (2012) Impaired ATP-induced coronary blood flow and diminished aortic NTPDase activity precede lesion formation in apolipoprotein E-deficient mice. Am J Pathol 180(1): 419-428. doi:10.1016/j.ajpath.2011.10.002

35. Bender SB, Tune JD, Borbouse L, Long X, Sturek M, Laughlin MH (2009) Altered mechanism of adenosine-induced coronary arteriolar dilation in early-stage metabolic syndrome. Exp Biol Med (Maywood) 234(6):683-692. doi:10.3181/0812-RM-350

36. Lewis CJ, Evans RJ (2001) P2X receptor immunoreactivity in different arteries from the femoral, pulmonary, cerebral, coronary and renal circulations. J Vasc Res 38 (4):332-340. doi:51064

37. Caligiuri G, Levy B, Pernow J, Thoren P, Hansson GK (1999) Myocardial infarction mediated by endothelin receptor signaling in hypercholesterolemic mice. Proc Natl Acad Sci U S A 96(12): 6920-6924

38. Zhang Q, Siroky M, Yang JH, Zhao Z, Azadzoi K (2014) Effects of ischemia and oxidative stress on bladder purinoceptors expression. Urology 84 (5):1249 e1241-1247. doi:10.1016/j.urology.2014.07. 023

39. You J, Wu J, Ge J, Zou Y (2012) Comparison between adenosine and isoflurane for assessing the coronary flow reserve in mouse models of left ventricular pressure and volume overload. Am J Physiol Heart Circ Physiol5 303(10):H1199-H1207. doi:10.1152/ ajpheart.00612.2012 